\title{
Состояние национальной инновационной системы России как повод к её институциональному совершенствованию
}

\author{
Григорьев Е.А. \\ Сибирский государственный университет водного транспорта, \\ Россия, 630099, г. Новосибирск, ул. Щетинкина, 33 \\ E-mail: e.a.grigorev@mail.ru
}

\begin{abstract}
Аннотация. В современном мире внедрение и развитие инноваций являются приоритетом для любого государства. Как правило, инновации связывают с высокотехнологичными отраслями информационные технологии, научные исследования и разработки. Вектор развития экономики Российской Федерации на современном этапе формируется, прежде всего, Стратегией инновационного развития РФ, в которой провозглашен инновационный путь развития, требующий постоянных новшеств и коммерциализации инноваций. Статья посвящена обзору современного состояния национальной инновационной системы (НИС) России. Определена роль инноваций в экономике страны; проанализирована инновационная активность стран и дана оценка НИС РФ; выявлены проблемы, препятствующие эффективности инновационной деятельности. В качестве решения проблемы несовершенства институтов рекомендовано создавать и внедрять новые институты, позволяющие стимулировать инновационную активность в имеющейся среде с привлечением новых экономических агентов.
\end{abstract}

Ключевые слова: инновационная экономика, инновационные технологии, национальная инновационная система, глобальный индекс инноваций.

Для цитирования: Григорьев Е.А. 2021. Состояние национальной инновационной системы России как повод к её институциональному совершенствованию. Экономика. Информатика, 48 (1): 34-43. DOI: 10.52575/2687-0932-2021-48-1-34-43.

\section{State of the national innovation system of Russia as a reason for its institutional improvement}

\author{
Evgeny A. Grigoriev \\ Siberian State University of Water Transport, \\ 33 Shchetinkina str., Novosibirsk, 630099, Russia \\ E-mail: e.a.grigorev@mail.ru
}

\begin{abstract}
In the modern world, the introduction and development of innovations are a priority for any state. as a rule, innovations are associated with high - tech industries-information technology, research and development. The vector of development of the economy of the Russian Federation at the present stage is formed, first, by the Strategy of Innovative Development of the Russian Federation, which proclaims an innovative way of development, requiring constant innovations and commercialization of innovations. The article is devoted to the review of the current state of the national innovation system (NIS) of Russia. The role of innovation in the country's economy is determined; the innovative activity of countries is analyzed, and the NIS of the Russian Federation is evaluated; the problems that hinder the effectiveness of innovation activity are identified. As a solution to the problem of imperfect institutions, it is recommended to create and implement new institutions that allow stimulating innovative activity in the existing environment with the involvement of new economic agents.
\end{abstract}

Keywords: innovative economy, innovative technologies, national innovation system, global innovation index. 
For citation: Grigoriev E.A. 2021. State of the national innovation system of Russia as a reason for its institutional improvement. Economics. Information technologies, 48 (1): 34-43 (in Russian). DOI: 10.52575/2687-0932-2021-48-1-34-43.

\section{Введение}

Устойчивое социально-экономическое развитие страны, ее конкурентоспособность невозможно без внедрения и развития инноваций. Инновационная активность государства является залогом успешного развития, обеспечивающего экономический рост, конкурентоспособность страны в мировом масштабе [Варакса, Залесова, 2019]. Инновации внедряются не только в наукоемких технологиях, они проникают во все сферы современного общества. Так, внедрение и развитие инноваций активно реализуется, прежде всего, через информационные и коммуникационные технологии в сфере здравоохранения, транспорта, образования, в бизнесе и государственной власти [Колотвинов, 2015]. То есть, используя научный потенциал, через взаимодействие частного и государственного сектора путем внедрения высоких технологий в различные сферы происходит трансформация на всех уровнях - на макро-, ме3о- и микроуровне, что находит отражение в основных показателях [Волкова, 2015; Дорошенко, Бережная, 2019; Кошелева, 2015; Храмцова, 2018; Drucker 2007; Gassmann et al., 2016].

Так как целью работы является краткий обзор современного состояния национальной инновационной системы (НИС) Российской Федерации, необходимо дать ее определение. Согласно институциональному подходу, под НИС понимают совокупность институтов, «относящихся к частному, общественным и государственным секторам, осуществляющих создание и реализацию инноваций (новых знаний и технологий) как индивидуально, так совместными усилиями в рамках конкретного государства» [Голиченко, 2012].

При этом выделяется ряд ключевых блоков организаций НИС: производственнотехнологический, инвестиционно-финансовый, кадровый, информационный, экспертноконсалтинговый [Волконицкая, Ляпина, 2014].

То есть только во взаимодействии различных сторон с обязательным участием государства, как регулятора этих взаимоотношений, возможно функционирование НИС. При этом роль государства заключается в формировании так называемых рамочных условий «создает ресурсы и институты, выступает как катализатор процессов в НИС партнер, снижающий инновационные риски» [Голиченко, 2012].

С учетом таких важных аспектов НИС как необходимость взаимодействия между различными сторонами, а также принимая во внимание важную роль государства, которое должно осуществлять, прежде всего, «управление системными связями, проектированием и управлением объектами инфраструктуры» [Фадейкина, Малина, 2020], можно дать следующее дополнить определение НИС. Авторское понятие НИС сводится к совокупности институтов на национальном уровне и взаимосвязей между организациями, осуществляющими производственно-технологические, инвестиционно-финансовые, кадровые, информационные, экспертно-консалтинговые функции, регулируемые государством для обеспечения инновационного развития страны.

\section{Основные результаты исследования}

Учитывая, что развитие страны на различных уровнях, как на культурном, политическом, так и технологическом, проходит по только присущей ей траектории, состояние и эволюция национальной инновационной системы (НИС) различаются. Этим и можно объяснить, что «трудно создать универсальную или оптимальную НИС для всех стран» [Альжанова, 2016; Nelson, 1993]. Существуют различные подходы, по которым можно проводить сравнительный анализ НИС. 
В целом выделяют четыре основных среза (подсистемы), по которым проводят оценку НИС: 1) научный потенциал; 2) инновационная инфраструктура; 3) инновационное предпринимательство; 4) финансовая инфраструктура [Притворова, Ситенко, 2010].

Основоположники концепции национальных инновационных систем выделяют различные по количеству и составу элементы. Так, Б.А. Лундвал предложил выделять шесть аспектов для сравнения НИС: 1) внутренняя организация фирм; 2) взаимодействия с другими фирмами; 3) государственный сектор; 4) финансовая инфраструктура; 5) научные исследования, разработки и их реализация; 6) национальная система образования и. К. Фримен при сравнении инновационных систем применял следующие основные критерии: 1) доля затрат на научные исследования и разработки в объеме ВВП; 2) доля участия промышленных предприятий в финансировании НИОКР; 3) состояние электронной промышленности; 4) доля иностранных инвестиций [Freeman, 1995].

Основные параметры инновационной активности России нашли отражение в целевых индикаторах реализации стратегии инновационного развития РФ на период до 2020 г. [Стратегия инновационного развития Российской Федерации на период до 2020 г.] (табл. 1).

Таблица 1

Table 1

Целевые индикаторы реализации Стратегии инновационного развития Российской Федерации на период до 2020 года

Target indicators for the implementation of the innovative development Strategy of the Russian Federation for the period up to 2020

\begin{tabular}{|c|c|c|c|c|c|c|c|c|c|c|c|}
\hline № & Наименование показателя & 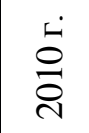 & $\stackrel{\dot{i}}{\vec{\sigma}}$ & $\stackrel{\dot{4}}{\stackrel{2}{\sigma}}$ & $\stackrel{\dot{m}}{\stackrel{\sim}{i}}$ & 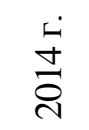 & $\stackrel{\dot{n}}{\stackrel{n}{i}}$ & 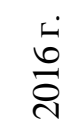 & $\stackrel{\dot{r}}{\stackrel{2}{\partial}}$ & $\stackrel{\dot{\infty}}{\stackrel{\infty}{0}}$ & 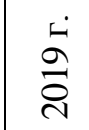 \\
\hline 1 & $\begin{array}{l}\text { Доля предприятий, осуществляющих } \\
\text { технологические инновации (от общего } \\
\text { количества предприятий) }\end{array}$ & 7,9 & 8,9 & 9,1 & 8,9 & 8,8 & 8,3 & 7,3 & $\begin{array}{l}20,8^{*} \\
(7,5)\end{array}$ & $19,6^{*}$ & $21,6^{*}$ \\
\hline 2 & $\begin{array}{l}\text { Доля затрат на технологические иннова- } \\
\text { ции (в общем объеме затрат на производ- } \\
\text { ство промышленного производства), \% }\end{array}$ & - & 1,5 & 1,8 & 2,2 & 2,1 & 1,8 & 1,8 & 1,7 & 1,5 & - \\
\hline 3 & $\begin{array}{l}\text { Внутренние затраты на исследования и } \\
\text { разработки (в \% от ВВП) }\end{array}$ & 1,13 & 1,02 & 1,05 & 1,03 & 1,07 & 1,10 & 1,10 & 1,11 & 1,0 & 1,03 \\
\hline 4 & $\begin{array}{l}\text { Внутренние затраты на исследования и } \\
\text { разработки по источникам финансирова- } \\
\text { ния: }\end{array}$ & & & & & & & & & & \\
\hline 4.1 & - бюджетные средства & 68,8 & 65,6 & 66,0 & 65,8 & 67,1 & 67,5 & 65,9 & 63,8 & 64,3 & 64,4 \\
\hline 4.2 & - внебюджетные средства & 31,2 & 34,4 & 34,0 & 34,2 & 32,9 & 32,5 & 34,1 & 36,2 & 35,7 & 35,6 \\
\hline 5 & $\begin{array}{l}\text { Коэффициент изобретательской активно- } \\
\text { сти (число поданных в РФ отечественных } \\
\text { патентных заявок на изобретения, в рас- } \\
\text { чете на } 10 \text { тыс. чел. населения) }\end{array}$ & 2,01 & 1,85 & 2,00 & 2,00 & 1,65 & 2,00 & 1,83 & 1,55 & 1,70 & 1,59 \\
\hline
\end{tabular}

* Примечание. Данные за 2017, 2018 и 2019 г. рассчитаны по новой методологии, что объясняется добавлением 2 дополнительных критериев отнесения предприятий к инновационным

Основные индикаторы, характеризующие инновационную деятельность, позволяют сделать вывод о том, что в целом произошли незначительные изменения в 2019 г. по сравнению с 2018 г. Так, доля предприятий, осуществляющих технологические инновации, начиная с 2017 г., возрастает и достигает 20,8\%, что обусловлено, прежде всего, добавлением двух дополнительных критериев при отнесении предприятий к инновационным, однако, при пересчете на методологии, действующей ранее, можно отметить, что рост произошел незначительный - всего $0,2 \%$. 
Другой важнейший индикатор, характеризующий инновационную сферу страны «внутренние затраты на исследования и разработки в процентах к ВВП» практически не меняется. Значение этого показателя, начиная с 2010 г. колеблется в пределах 1,0-1,13\% и в 2019 г. составило всего 1,03\%. Россия значительно отстает от ведущих стран мира, в 2-3 раза. В то время как аналогичный показатель (в 2018 г.) - в Германии 3,103\%, Швейцарии 3,293\%, Швеции -3,321\%, Нидерланды -2, 164\% [OECD, 2018] (рис. 1).

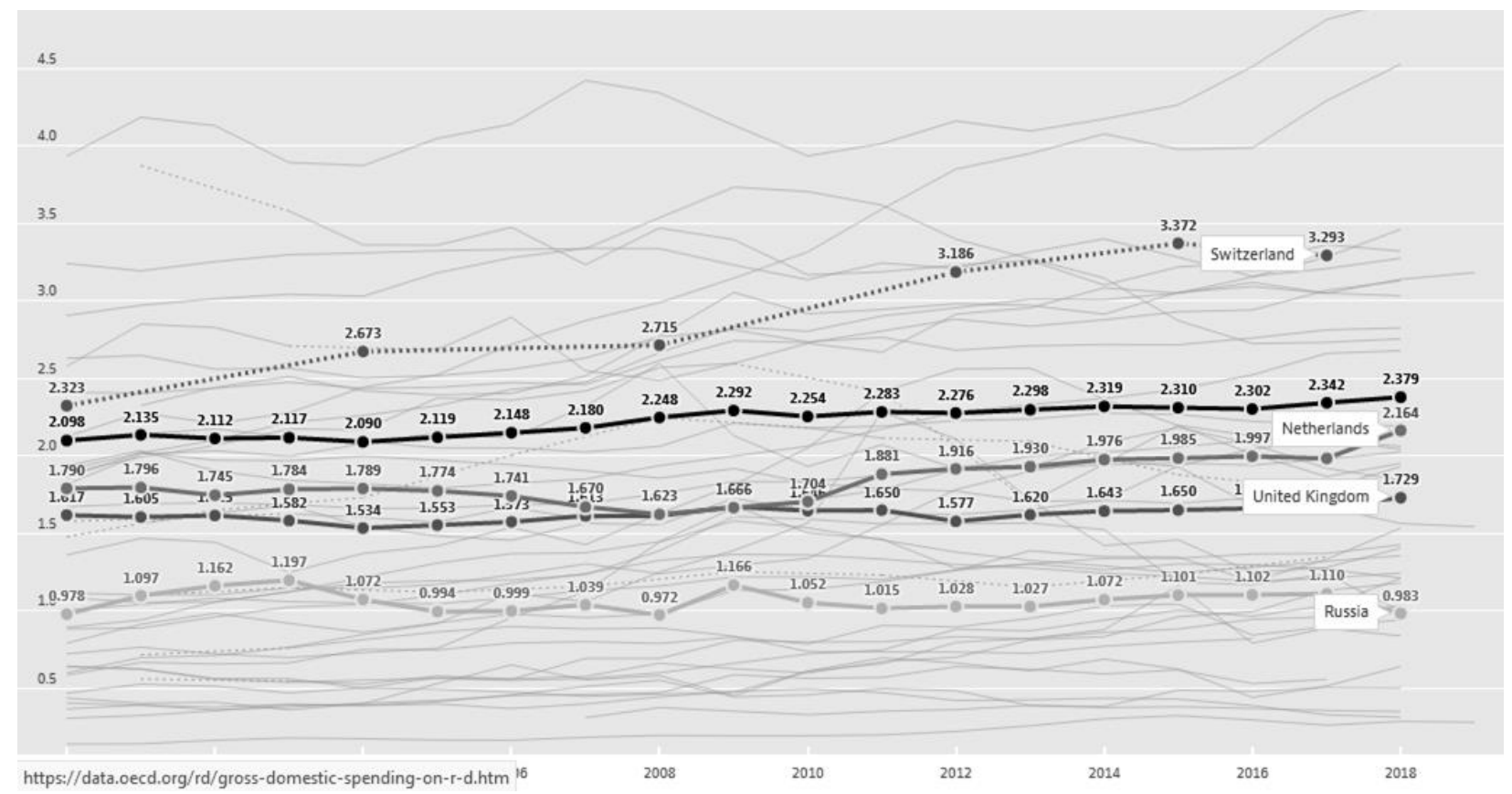

Рис. 1. Валовые внутренние расходы на НИОКР, \%

Fig. 1. Gross domestic expenditure on R \& d, \%

Для анализа инновационной активности стран и возможности сопоставления разработаны различные агрегатные индексы. Существуют различные международные индексы; к ним относят Европейскую шкалу инноваций (EIS), глобальный инновационный индекс, индекс глобальной конкурентоспособности [Рудаенко, Подкуйко, 2018].

Наиболее информативным и распространенным для оценки и сопоставления инновационного развития страны является Глобальный индекс инноваций (The Global Innovation Index, далее ГИИ). Его разработчиками явились INSEAD - международная бизнес-школа, школа бизнеса Университетом Корнелл, и Всемирная организация интеллектуальной собственности (WIPO). В ГИИ нашли отражение различные аспекты инновационного развития той или иной страны, как развитых, так и развивающихся. Оценка проводится, начиная с 2007 г. с использованием 80 различных критериев и показателей, на основе которых формируются два субиндекса - субиндекс располагаемых инновационных ресурсов и субиндекс достигнутых результатов реализации инноваций. Для оценки инновационных ресурсов исследуются такие характеристики как: 1) человеческий капитал, 2) институты 3) инфраструктура, 4) состояние внутреннего рынка 5) развитость бизнеса. При исследовании инновационных результатов анализируются развитость технологий и экономики знаний, а также состояние креативной деятельности. В свою очередь для определения глобального индекса инноваций рассчитывается среднее значение двух субиндексов. Глобальный индекс определяется для 131 стран, начиная с 2007 г.

Примечательно, что сравнительный анализ проводится по группам стран, сформированных по уровню дохода и по региональному признаку. С точки зрения группировки по уровню дохода выделяют четыре группы стран: 1) с высоким уровнем доходов (49), 2) с доходом выше среднего (37), 3) с низким средним уровнем доходов (29) и 4) с низким уровнем доходов (16). 
Пандемия коронавирусной болезни (COVID-19) вызвала беспрецедентный глобальный экономический спад. Как полагают авторы отчета, формируемого по глобальному индексу инноваций ежегодно, кризис может стать катализатором во многих традиционных секторах, таких как туризм, образование, розничная торговля.

Несмотря на это, на протяжении многих лет лидирующие позиции по Глобальному индексу в 2020 г. занимают Швейцария, Швеция, США, Соединенное Королевство и Нидерланды. Это объясняется, прежде всего, значительной государственной поддержкой и системой льгот при внедрении инноваций.

Россия в 2020 г. включена в группу стран «с доходом выше среднего» и занимает 6 позицию среди 37 стран этой группы [Глобальный индекс инноваций, 2020] (табл. 2).

Таблица 2

Table 2

Страны-лидеры по уровню доходов за 2020 г.

Leading countries in terms of income for 2020

\begin{tabular}{|l|c|l|l|l|l|l|l|}
\hline \multicolumn{2}{|l|}{ С высоким доходом } & \multicolumn{2}{|l|}{ С доходом выше среднего } & \multicolumn{2}{c|}{$\begin{array}{l}\text { С доходами ниже } \\
\text { среднего }\end{array}$} & \multicolumn{2}{l|}{ С низким уровнем доходов } \\
\hline Швейцария & 1 & Китай & 14 & Вьетнам & $\begin{array}{l}\text { Объединенная респуб- } \\
\text { лика Танзания }\end{array}$ & 88 \\
\hline Швеция & 2 & Малайзия & 33 & Украина & 45 & Руанда & 91 \\
\hline США & 3 & Болгария & 37 & Индия & 48 & Непал & 95 \\
\hline Великобритания & 4 & Тайланд & 44 & Филиппины & 50 & Таджикистан & 109 \\
\hline Нидерланды & 5 & Румыния & 46 & Монголия & 58 & Малави & 111 \\
\hline Дания & 6 & Российская Федерация & 47 & $\begin{array}{l}\text { Молдавская } \\
\text { республика }\end{array}$ & 59 & Уганда & 114 \\
\hline Финляндия & 7 & Черногория & 49 & Тунис & 65 & Мадагаскар & 115 \\
\hline Сингапур & 8 & Турция & 51 & Марокко & 75 & Буркина Фасо & 118 \\
\hline Германия & 9 & Маврикий & 52 & Индонезия & 85 & Мали & 123 \\
\hline Республика & 10 & Сербия & 53 & Кения & 86 & Мозамбик & 124 \\
\hline
\end{tabular}

В основе другой группировки - региональный признак - по этому признаку выделяют 7 групп: 1) Северная Америка, 2) Европа, 3) Юго-Восточная Азия и Океания, 4) Северная Африка и Западная Азия, 5) Латинская Америка и Карибский бассейн, 6) Южная Африка и Caхара, 7) Центральная и Южная Азия. Различие в инновационном развитии среди различных групп, как по уровню доходов, так и по региональному признаку превышает более чем в 2 раза. Российская Федерация заняла 32 место из 39.

Анализируя динамику глобального индекса инноваций РФ за 3 года, отметим, что у Российской Федерации индекс снизился на 1 позицию, с 46 на 47 место. В 2020 г. Российская Федерация занимает 42 место по объему инновационных ресурсов инноваций, что ниже, чем в прошлом году, но выше, чем в 2018 г. По субиндексу «результаты инноваций» Россия занимает 58 место.

Сделав более подробный анализ, можно увидеть, что только по одному критерию «человеческий капитал и исследования» высокий рейтинг (30-е место). По категориям «развитие бизнеса», «знания и создание технологий», а также «креативная деятельность», «инфраструктура» значения выше среднего в соответствующей группе стран.

По сравнению с другими странами Европы Российская Федерация занимает только по одному элементу позицию выше среднего «Человеческий капитал и исследования», по остальным составляющим значения ниже среднего (рис. 2). 


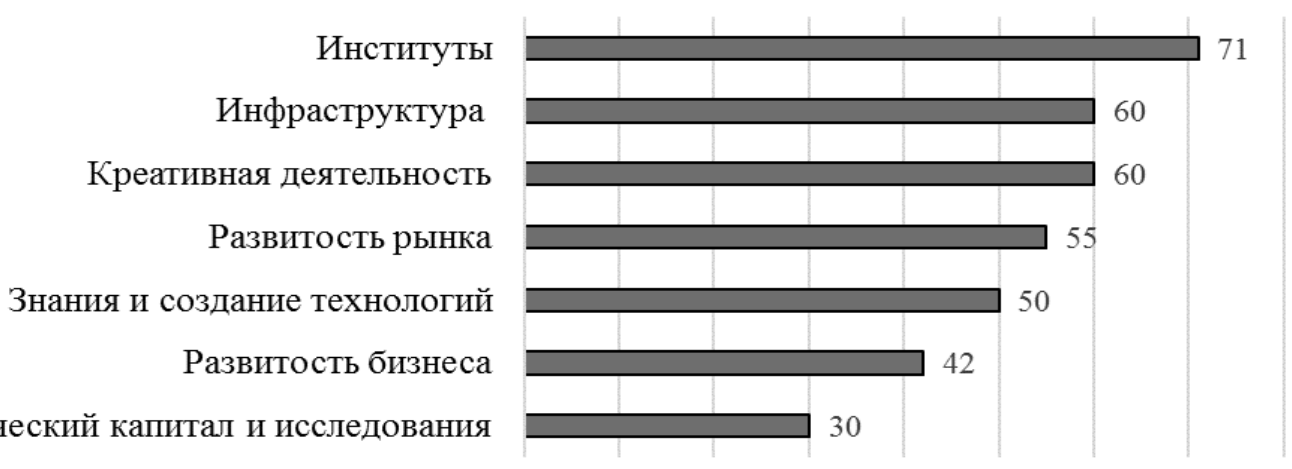

Рис. 2. Рейтинг РФ в 2020 г. по семи составляющим Глобального индекса инноваций

Fig. 2. Russia's rating in 2020 for seven components of the Global innovation index

Исследуя сильные стороны, можно выделить наличие квалифицированных кадров по количеству выпускников по естественным и техническим наукам (15 место), доступность высшего образования (17 место), соотношение учащихся и учителей (19 место).

Высокие потенциальные возможности в области научных исследований - число патентных заявок, поданных в патентные ведомства страны (17 место), по наличию полезных моделей -9 место. Так, несмотря на рост поданных патентных заявок по промышленным образцам и полезным моделям, общее количество поданных заявок снизилось в 2019 г. на 1045 (по сравнению с 2018 г.) и составило 52567, что обусловлено снижением поданных заявок по изобретениям, число выданных патентов в 2019 г. также снизилось - 48251 (в 2018 г. 51946 шт., табл. 3) [Роспатент: цифры, факты и проекты, 2019]

Таблица 3

Table 3

Количество поданных патентных заявок и выданных патентов*

Number of patent applications filed and patents granted*

\begin{tabular}{|c|c|c|c|}
\hline Наименование & 2019 & 2018 & 2017 \\
\hline Промышленные образцы, подано заявок & 6920 & 5908 & 6487 \\
выдано патентов & 5395 & 6305 & 5339 \\
\hline Изобретения: подано заявок & 35511 & 37957 & 36454 \\
выдано патентов & 34008 & 35774 & 34254 \\
\hline Полезные модели: подано заявок & 10136 & 9747 & 10643 \\
выдано патентов & 8848 & 9867 & 8774 \\
\hline
\end{tabular}

* Составлено по данным официального сайта Роспатент: цифры, факты и проекты

Это в совокупности характеризует высокий научный потенциал, позволяющий получить высокую эффективность инновационной деятельности.

Несмотря на огромный инновационный потенциал в области - зарегистрировано значительное количество патентов, реализация инновационной деятельности в этой сфере находится на невысоком уровне.

Однако слабое развитие такой сферы как «институты» (71-е место) препятствует эффективности инновационной деятельности. Как справедливо отмечают исследователи из Высшей школы экономики, экономическое и социальное состояние той или иной страны во многом зависит от уровня развитости институтов.

Характеристика состояния институтов характеризуется следующими параметрами элементов (табл. 4).

Наиболее слабо развита регулирующая среда (95 место среди 131 страны), что определяется, прежде всего, верховенством права (114 место) и качеством законодательной базы (105 место). 
Рейтинг элементов категории «институты» Глобального инновационного Индекса в 2020 г.

Ranking of elements of the «institutions» category of the Global Innovation Index in 2020

\begin{tabular}{|l|c|c|}
\hline \multicolumn{1}{|c|}{ Элементы } & $\begin{array}{c}\text { Место } \\
\text { среди 131 страны }\end{array}$ & $\begin{array}{c}\text { 3начение } \\
(0-100)\end{array}$ \\
\hline 1. Политическая среда & 75 & 54,5 \\
1.1. Политическая стабильность & 76 & 66,1 \\
1.2. Эффективность государственного управления & 75 & 48,8 \\
\hline 2. Регулирующая среда & 95 & 54 \\
2.1. Качество законодательной базы & 105 & 27,5 \\
2.2. Верховенство права & 114 & 25,4 \\
2.3. Затраты, связанные с сокращением штатных & 69 & 17,3 \\
сотрудников & & \\
\hline
\end{tabular}

Несмотря на то, что принимаются все новые и новые законы, российская правовая база является довольно несовершенной. Слабо развита законодательная база в области бюджетного, налогового и таможенного регулирования; недостаточно сформированы условия для развития малого бизнеса, а также с отсутствием взаимосвязи между законодательными актами.

Несмотря на то, что в 2003-2004 гг. были приняты различные нормативно-правовые акты в области административной реформы, в которых прописаны более «однозначные полномочия и ответственность, а также принципы государственной службы», эффективность государственной управления остается на весьма низком уровне (75-е место).

Весьма высокая коррупционная составляющая. Уровень коррупции в России довольно высокий, значительная часть экономики находится в «черной зоне». Так, в начале $2000-x$ гг. «объем коррупционных издержек в российской экономике составлял до $10 \%$ ВВП». И несмотря на то, что статистика свидетельствует о снижении на 25\% числа выявленных нарушений, оборот коррупционного рынка вырос в 100 раз (порядка 3 млрд долларов в 2003 г. против более 300 млрд долл. на 2020 г.). В большинстве случаев коррупционные преступления вызваны существующими пробелами в законодательной базе РФ.

О состоянии уровня коррупции также может свидетельствовать Индекс восприятия коррупции (ИВК), который публикуется в Отчетах международной неправительственной организации Transparency International [Индекс восприятия коррупции, 2020]. Россия в Индексе восприятия коррупции-2020 заняла 129 место.

В качестве рекомендаций можно предложить следующее - ввести в Российской Федерации антикоррупционное воспитание, опираясь на опыт Дании. В силу того, что в Дании реализуется проект «Образование против коррупции», она занимает первые позиции в международных антикоррупционных рейтингах.

\section{Заключение}

Подводя итоги, следует отметить, что сложившаяся ситуация обусловлена следующими причинами: политическая нестабильность в стране, механизм государственного регулирования инновационных процессов и развития НИС в России не сформирован в должной мере, приняты лишь отдельные концептуальные и стратегические документы. Более того, меры, предпринятые государством по трансформированию институтов, не привели к должным результатам. Проблема институтов является довольно глубокой, многоаспектной и комплексной, более того, решение ее может занять довольно длительное время.

Как было отмечено ранее, в соответствии с институциональным подходом в повышении уровня инновационного развития России значительную роль играет государство и законодательство, поэтому все усилия должны быть направлены на развитие институтов, необ- 
ходимо наладить взаимоотношения между элементами через реализацию аспектов инновационного развития РФ. Учитывая трудность и длительную протяженность по времени институциональных изменений, необходимо «правильно использовать знания - не только технологические, но и организационно-управленческие и экономические». Проанализировав опыт стран с близкой к России несовершенной институциональной средой (Чили, Мексика, Бразилия), и преломив через призму применимости к нашей стране, найти «собственное оригинальное решение». В качестве решения проблемы несовершенства институтов можно порекомендовать создавать и внедрять новые институты, позволяющие стимулировать инновационную активность в имеющейся среде с привлечением новых экономических агентов.

\section{Список литературы}

1. Альжанова Ф.Г. 2016. Национальные инновационные системы: сравнительный анализ на базе глобального индекса. Экономика: стратегия и практика. 2 (38): 6-16.

2. Варакса А.М., Залесова Д.Р. 2019. Возможность переходя российской экономики к инновационной системе развития в условиях современного эконмического кризиса. Актуальные вопросы развития инновационной экономики. Сборник статей Всероссийской научно-практической конференции. Новгородский государственный университет имени Ярослава Мудрого: 76-80.

3. Волкова С.В. 2015. Факторы, влияющие на внедрение инноваций в России. В сборнике: Актуальные вопросы современной науки. Сборник научных докладов 21-ой научно-практической конференции: 104-106.

4. Волконицкая К.Г., Ляпина С.Ю. 2014. Развитие региональных инновационных систем. Интернет-журнал «НАУКОВЕДЕНИЕ». 5 (24): 1-19.

5. Глобальный индекс инноваций. 2020. [Электронный pecypc]. URL: https://www.globalinnovationindex.org (Дата обращения 30.11.2020).

6. Голиченко О.Г. 2012. Основные факторы развития национальной инновационной системы России. Инновации. 5 (163): $4-18$.

7. Дорошенко Ю.А., Бережная А.В. 2019. Условия и факторы инновационного развития региона. В кн.: Экономика. Общество. Человек. Типы научной рациональности в информационном обществе: методологические аспекты. Материалы Всероссийской научно - практической конференции с международным участием. Вып. XXXVII. T. 2. Белгород, Изд - во БГТУ: 109 - 115.

8. Индекс восприятия коррупции (ИВК) // Отчет международной неправительственной организации $\quad$ Transparency International. $\quad-\quad 2020 . \quad-\quad$ URL: https://transparency.org.ru/research/CPI2020_Report_RU\%20[WEB].pdf

9. Колотвинов А.Н. 2015. Проблемы внедрения инноваций в России. NovaInfo.Ru. T.1. 32: 90-92.

10. Кошелева Т.Н. 2015. Инновационная политика как фактор развития малого предпринимательства. Экономика и управление. 4 (90): 75-78.

11. Кузнецов Е. 2002. Пробудиться, догнать и устремиться вперед: Механизмы запуска инновационного роста России. Препринт WP5/2002/07. М.: ГУВШЭ, 2002, 68.

12. Кузьминов Я.И., Радаев В.В., Яковлев А.А., Ясин Е.Г. 2005. Институты: От заимствования к выращиванию: Опыт российских реформ и возможное культивирование институциональных изменений. М.: ГУВШЭ: 5-27.

13. Маремкулова А.3. 2020. Коррупция в России // Научный электронный журнал Меридиан 4 (38): 9-11.

14. Притворова Т.П., Ситенко Д.А. 2010. Сравнительный анализ методических подходов к оценке эффек-тивности национальной инновационной системы. АльПари. 4: 68-73.

15. Рудаенко В.Е., Подкуйко К.В. 2018. Информационно-аналитический обзор инновационной сферы стран мира на основе глобального индекса инноваций за 2017 г. В сборнике: Актуальные проблемы современности. материалы 13-й Всероссийской научно-практической конференции «Альтернативный мир». Ответственный редактор Д.В. Буяров: 146 - 157.

16. Состояние преступности в России // Сборник Главного управления правовой статистики и информационных технологий. $\quad$ т 2019.2 https://genproc.gov.ru/upload/iblock/034/sbornik_12_2019.pdf

17. Состояние преступности в России // Сборник Главного управления правовой статистики и информационных технологий. $\quad$ т $2020 . \quad$ - URL: https://genproc.gov.ru/upload/iblock/925/sbornik_9_2020.pdf 
18. Фадейкина Н.В., Малина С.С. 2020. О национальной инновационной системе и реализации стратегии инновационного развития Российской Федерации на период до 2020 года. Непрерывное профессиональное образование и новая экономика. 1(6): 3-14.

19. Храмцова Н.А. 2018. Развитие инновационной деятельности предприятий. Стратегии бизнеса. 7 (51): 23-26.

20. Целевые индикаторы реализации Стратегии инновационного развития Российской Федерации на период до 2020 года: Федеральная служба государственной статистики. [Электронный pecypc] URL: http://old.gks.ru/wps/wcm/connect/ rosstat_main/rosstat/ru/statistics/science_and_innovations/science/ (Дата обращения 29.11.2020).

21. Роспатент: цифры, факты и проекты [Электронный pecypc]. URL: https://rospatent.gov.ru/content/ uploadfiles /annual-report-2019-short-version.pdf (Дата обращения 02.12.2020).

22. Drucker P.F. 2007. Innovation and entrepreneurship: practice and principles. Amsterdam [etc.]: Elsevier; Oxford: Butterworth - Heinemann, 253.

23. Freeman, C. 1995. The «National System of $I n \neg$ novation» in Historical Perspective. Cambridge Journal of Economics. 19: 5 - 24.

24. Gassmann Oliver, Frankenberger Karolin, Sauer Roman. 2016. Exploring the Field of Business Model Innovation: New Theoretical Perspectives PDF. Palgrave Macmillan, 126 p.

25. Nelson R. 1993. National Innovation Systems. Oxford, Oxford University Press, 541.

26. OECD, 2018. Gross domestic spending on R\&D: OECD Publishing.

\section{References}

1. Alzhanova, F. G. 2016. National innovation systems: comparative analysis based on the global index. Economics: Strategy and Practice. 2 (38): 6-16.

2. Varaksa A.M., Zalesova D. R. 2019. The possibility of the transition of the Russian economy to an innovative system of development in the conditions of the current economic crisis. Current issues of innovative economy development. Collection of articles of the All-Russian Scientific and Practical Conference. Yaroslav the Wise Novgorod State University: 76-80.

3. Volkova S. V. 2015. Factors influencing the introduction of innovations in Russia. In the collection: Topical issues of modern science. Collection of scientific reports of the 21 st scientific and practical conference: $104-106$.

4. Volkonitskaya K. G., Lyapina S. Yu. 2014. Development of regional innovation systems. Online journal "SCIENCE Studies". 5 (24): 1-19.

5. Global Innovation Index. 2020. [Electronic resource]. URL: https://www.globalinnovationindex.org (Accessed 30.11.2020).

6. Golichenko O. G. 2012. The main factors of the development of the national innovation system of Russia. Innovation. 5 (163): $4-18$.

7. Doroshenko Yu. A., Berezhnaya A.V. 2019. Conditions and factors of innovative development of the region. In: Economics. Society. Person. Types of scientific rationality in the information society: methodological aspects. Proceedings of the All-Russian Scientific and Practical Conference with International participation. Issue XXXVII. 2. Belgorod, BSTU Publishing House: 109-115.

8. Corruption Perception Index (CPI) / / Report of the international non-governmental organization Transparency International. 2020. https://transparency.org.ru/research/CPI2020_Report_RU\%20[WEB].pdf

9. Kolotilov A. N. 2015. Problems of innovation implementation in Russia. NovaInfo. Ru. Te. 1. 32: 90-92.

10. Kosheleva T. N. 2015. Innovation policy as a factor of small business development. Economics and Management. 4 (90): 75-78.

11. Kuznetsov E. 2002. Wake up, catch up and Rush forward: Mechanisms for Launching Russia's Innovative Growth. Preprint WP5 / 2002 / 07. Moscow: GUVSHE, 2002, 68.

12. Kuzminov Ya. I., Radaev V. V., Yakovlev A. A., Yasin E. G. 2005. Institutions: From borrowing to cultivation: The experience of Russian reforms and possible cultivation of institutional changes. Moscow: GUVSHE: $5-27$.

13. Maremkulov A. Z. 2020. Corruption in Russia / / Scientific electronic journal Meridian 4 (38): 9-11.

14. Pritvorova T. P., Sitenko D. A. 2010. Comparative analysis of methodological approaches to assessing the effectiveness of the national innovation system. Alpari. 4: 68-73. 
15. Rudaenko V. E., Podkuiko K. V. 2018. Information and analytical review of the innovation sphere of the countries of the world based on the global innovation index for 2017 In the collection: Actual problems of our time. materials of the 13th All-Russian scientific and Practical Conference "Alternative World". Executive editor D. V. Buyarov: 146-157.

16. The state of crime in Russia / / Collection of the Main Department of Legal Statistics and Information Technologies. - 2019. - URL: https://genproc.gov.ru/upload/iblock/034/sbornik_12_2019.pdf

17. The state of crime in Russia / / Collection of the Main Department of Legal Statistics and Information Technologies. - 2020. - URL: https://genproc.gov.ru/upload/iblock/925/sbornik_9_2020.pdf

18. Fadeikina N. V., Malina S. S. 2020. On the national innovation system and the implementation of the strategy of innovative development of the Russian Federation for the period up to 2020. Continuing professional education and the new economy. 1(6): 3-14.

19. Khramtsova N. A. 2018. Development of innovative activity of enterprises. Business strategies. 7 (51): 23-26.

20. Target indicators of the implementation of the Strategy of Innovative Development of the Russian Federation for the period up to 2020: Federal State Statistics Service. [Electronic resource] URL: http://old.gks.ru/wps/wcm/connect/ rosstat_main/rosstat / ru/statistici/science_and_innovations/en / (Accessed 29.11.2020).

21. Rospatent: figures, facts and projects [Electronic resource]. URL: https://rospatent.gov.ru/content/ uploadfiles /anual-raport-2019-scurt-versiune. pdf (Accessed 02.12.2020).

22. Drucker P. F. 2007. Inovație și antreprenoriat: practică și principii. Amsterdam [etc.]: Elsevier; Oxford: Butterworth-Heinemann, 253.

23. Freeman, C. 1995. "Sistemul Național de inovare" în perspectivă istorică. Cambridge Jurnalul de Economie. 19: 5 - 24 .

24. Gassmann Oliver, Frankenberger Karolin, Sauer Roman. 2016. Explorarea domeniului Inovarii modelului de afaceri: noi perspective teoretice PDF. Palgrave Macmillan, $126 \mathrm{p}$.

25. Nelson R. 1993. Sisteme Naționale De Inovare. Oxford, Oxford University Press, 541.

26. OCDE, 2018. Cheltuielile interne brute pentru cercetare și dezvoltare: OCDE Publishing.

\section{ИНФОРМАЦИЯ ОБ АВТОРЕ}

\begin{tabular}{|c|c|c|}
\hline $\begin{array}{l}\text { Григорьев I } \\
\text { Экономически } \\
\text { «Экономика }\end{array}$ & $\begin{array}{l}\text { Евгений A } \\
\text { Ix наук, }\end{array}$ & $\begin{array}{cc}\text { Алексеевич, } & \text { канд } \\
\text { доцент } & \text { каф } \\
\text { предприниматель }\end{array}$ \\
\hline ности» & ФГБОУ & «Сиб \\
\hline
\end{tabular}

транспорта», г. Новосибирск

\section{INFORMATION ABOUT THE AUTHOR}

Evgeny A. Grigoriev, candidate of economic Sciences, Associate Professor of the Department of Business Economics Siberian State University of Water Transport, Novosibirsk 